\title{
Blood Products Provided to Patients Receiving Futile Critical Care
}

\author{
Thanh H. Neville, MD, MSHS ${ }^{1 *}$, Alyssa Ziman, MD², Neil S. Wenger, MD, MPH ${ }^{3,4,5}$
}

\begin{abstract}
${ }^{1}$ Department of Medicine, Division of Pulmonary and Critical Care Medicine, David Geffen School of Medicine, University of California Los Angeles, Los Angeles, California; '2Department of Pathology and Laboratory Medicine, David Geffen School of Medicine, University of California Los Angeles, Los Angeles, California; ' ${ }^{3}$ niversity of California Health Ethics Center, Los Angeles, California; ${ }^{4}$ Deparment of Medicine, Division of General Internal Medicine and Health Services Research, David Geffen School of Medicine, University of California Los Angeles, Los Angeles, California; ${ }^{5}$ RAND Health, Santa Monica, California.
\end{abstract}

The number of hospitalized patients receiving treatment perceived to be futile is not insignificant. Blood products are valuable resources that are donated to help others in need. We aimed to quantify the amount of blood transfused into patients who were receiving treatment that the critical care physician treating them perceived to be futile. During a 3-month period, critical care physicians in 5 adult intensive care units completed a daily questionnaire to identify patients perceived as receiving futile treatment. Of 1136 critically ill patients, physicians assessed 123 patients (11\%) as receiving futile treatment. Fifty-nine (48\%) of the 123 patients received blood products after they were assessed to be receiving futile treatment: 242 units of packed red blood cells (PRBCs) (7.6\% of all PRBC units transfused into critical care patients during the 3-month study period); 161 (9.9\%) units of plasma, $137(12.1 \%)$ units of platelets, and $21(10.5 \%)$ units of cryoprecipitate. Explicit guidelines on the use of blood products should be developed to ensure that the use of this precious resource achieves meaningful goals. Journal of Hospital Medicine 2017;12:739-742. (C) 2017 Society of Hospital Medicine
Critical care physicians frequently find themselves providing care that they find to be futile or inappropriate for hospitalized critically ill patients. A survey of physicians found that $87 \%$ felt that "futile" treatment was provided in their intensive care unit (ICU) in the past year. ${ }^{1}$ In a single-day cross-sectional study, $27 \%$ of ICU clinicians reported providing inappropriate care to at least 1 patient, most of which was excessive. ${ }^{2}$ In a 3 -month study, $11 \%$ of all ICU patients were perceived by their physician as receiving futile treatment at some point during their ICU hospitalization. ${ }^{3}$ Given that more than 1 in 5 decedents die after an ICU stay during a terminal admission, there is increasing scrutiny of the ICU as a setting where potentially inappropriate resource-intensive treatment is provided. ${ }^{4-6}$ Blood is an especially valuable resource, not only because it exists in finite supply (and is sometimes in shortage) but also because it is donated in ways that arguably create special stewardship expectations and responsibilities for those trusted to make decisions about its use. The amount of blood products used for patients who are perceived to be receiving inappropriate critical care has not been quantified.

Blood transfusion is the most frequently performed inpatient procedure, occurring in more than $10 \%$ of hospital admissions that involve a procedure. ${ }^{7}$ When used appropri-

\footnotetext{
*Address for correspondence and reprint requests: Thanh $\mathrm{H}$. Neville, MD, MSHS, Department of Medicine, Division of Pulmonary and Critical Care Medicine, Box 951690, 37-131 CHS, Los Angeles, CA 90095-1690; Telephone: 310-825-859; Fax 310-206-8622; E-mail: tneville@mednet.ucla.edu
}

Received: November 30, 2016; Revised: March 14, 2017;

Accepted: March 29, 2017

2017 Society of Hospital Medicine DOI 10.12788/jhm.2820 ately, the transfusion of blood products can be lifesaving; however, studies show that some transfused blood might not be needed and efforts are afoot to improve the match between transfusion and transfusion need. ${ }^{8,9}$ These efforts largely focus on generating guidelines based on physiologic benefit and aim mainly at promoting a restrictive transfusion protocol by avoiding blood product use for patients who will likely do well even without transfusion. ${ }^{8,10-12}$ The guiding principle behind efforts to improve the stewardship of scarce blood products is that they should only be used if they will make a difference in patient outcomes. Unlike prior studies, the goal of this study is to quantify the amount of blood products administered to patients who would do poorly with or without receipt of blood products, that is, patients perceived by their physicians as receiving futile critical care.

\section{MATERIALS AND METHODS}

Based on a focus group discussion with physicians who cared for critically ill patients, a questionnaire was developed to identify patients perceived as receiving futile critical care. Details of the definition of futile treatment and the core data collection are described in detail elsewhere. ${ }^{3}$

For each ICU patient under the physician's care, the attending physician completed a daily questionnaire asking whether the patient was receiving futile treatment, probably futile treatment, or nonfutile treatment. These surveys were administered every day from December 15, 2011, through March 15, 2012, to each critical care specialist providing care in 5 ICUs (medical ICU, neurocritical care ICU, cardiac care unit, cardiothoracic ICU, and a mixed medical-surgical ICU) in 1 academic health system. All clinicians provided informed consent.

Patients were categorized into the following 3 groups: pa- 
TABLE. Quantity of Blood Products Administered to Patients Who Were Assessed during the 3-Month Study Period

\begin{tabular}{lcc}
\hline $\begin{array}{l}\text { Blood Product } \\
\text { Packed red blood cells }\end{array}$ & 3179 & $\begin{array}{c}\text { Units Transfused after Patient Assessed } \\
\text { as Receiving Probably Futile Treatment }\end{array}$ \\
\hline $\begin{array}{l}\text { Fresh frozen plasma } \\
\text { Platelets }\end{array}$ & 1624 & $247(10.9 \%)$ \\
\hline Cryoprecipitate & 1130 & $243(15 \%)$ \\
\hline $\begin{array}{l}\text { aBecause patients usually were assessed as receiving probably futile treatment before being assessed as receiving futile treatment, blood products received after a patient was assessed as receiving futile treatment (column 3) is a subset } \\
\text { as Receiving Futile Treatment }\end{array}$ & $189(16.7 \%)$ \\
$\begin{array}{l}\text { of blood products received after a patient was assessed as receiving futile treatment (column 2). } \\
\text { NOTE: Percentages in parenthesis refer to proportion of product usage by patients who were perceived as receiving futile critical care. }\end{array}$ \\
\hline
\end{tabular}

tients for whom treatment was never perceived as futile; patients with at least 1 assessment that treatment was probably futile, but no futile treatment assessments; and patients who had at least 1 assessment of futile treatment. Hospital and 6-month mortality was abstracted for all patients.

The Division of Transfusion Medicine provided a database of all adult patients during the 3-month study period who received a transfusion of packed red blood cells (PRBCs), apheresis platelets, plasma, or cryoprecipitate (5 unit prepooled units). This database was merged with the daily assessments of the appropriateness of critical care. To determine the proportion of blood products that was utilized for patients receiving inappropriate treatment, we tallied the blood products infused to these patients after the day the patient was assessed as receiving probably inappropriate or inappropriate treatment. The denominator was the total amount of blood products used by all assessed patients during the 3-month study period.

This study was approved by the University of California Los Angeles Institutional Review Board (IRB\# 11-002942CR-00004).

\section{RESULTS}

During the 3-month study period, 36 critical care clinicians in 5 ICUs provided care to 1193 adult patients. After excluding boarders in the ICUs and missed and invalid assessments, 6916 assessments were made on 1136 patients. Of these 1136 patients, $98(8.6 \%)$ patients received probably futile treatment and $123(11 \%)$ patients received futile treatment according to the physicians caring for them.

For patients who were never rated as receiving futile treatment, the in-hospital mortality was $4.6 \%$ and the 6 -month mortality was $7.3 \%$. On the contrary, $68 \%$ of the patients who were perceived to receive futile ICU treatment died before hospital discharge and 85\% died within 6 months; survivors remained in severely compromised health states. ${ }^{3}$

Of 1136 patients, $595(52.4 \%)$ patients received at least 1 unit of blood product infusion during the 3-month period. These patients received 3179 units of PRBCs, 1624 units of plasma, 1130 units of platelets, and 201 units of cryoprecip- itate. Of the 123 patients assessed as receiving futile critical care, $59(48.0 \%)$ patients received blood product infusions during the study period after they were assessed as receiving futile treatment. Eighteen of these patients $(30.5 \%)$ were in surgical ICUs and $41(69.5 \%)$ were in medical and neuro-ICUs. After being classified as receiving futile critical care, these patients were transfused 242 units of PRBCs, which was $7.6 \%$ of the PRBCs received by the study cohort. The mean number of blood products (PRBC, fresh frozen plasma, platelet, or cryoprecipitate) transfused per patient was 9.8 units (range 1-80) with $56 \%$ of patients receiving less than 4 units. Patients assessed as receiving futile treatment also received 161 (9.9\%) units of plasma, $137(12.1 \%)$ units of platelets, and $21(10.5 \%)$ units of cryoprecipitate (Table, which also shows the amount of blood utilized after the patient had an assessment of probably futile treatment). Patients who received blood products after they were assessed as receiving futile treatment had a 6-month mortality of $95 \%$. The figure shows the derivation of the study sample, blood products received and patient outcomes.

\section{DISCUSSION}

Blood and blood products are donated resources. These biological products are altruistically given with the expectation that they will be used to benefit others. ${ }^{13}$ It is the clinicians' responsibility to use these precious gifts to achieve the goals of medicine, which include curing, preserving function, and preventing clinical deterioration that has meaning to the patient. Our study shows that a small, but not insignificant, proportion of these donated resources are provided to hospitalized patients who are perceived as receiving futile critical care. That means that these transfusions are used as part of the critical care interventions that prolong the dying process and achieve outcomes, such as existence in coma, which few, if any, patients would desire. However, it should be noted that some of the health states preserved, such as neurological devastation or multi-organ failure with an inability to survive outside an ICU, were likely desired by patients' families and might even have been desired by patients themselves. Whether blood donors would wish to donate 


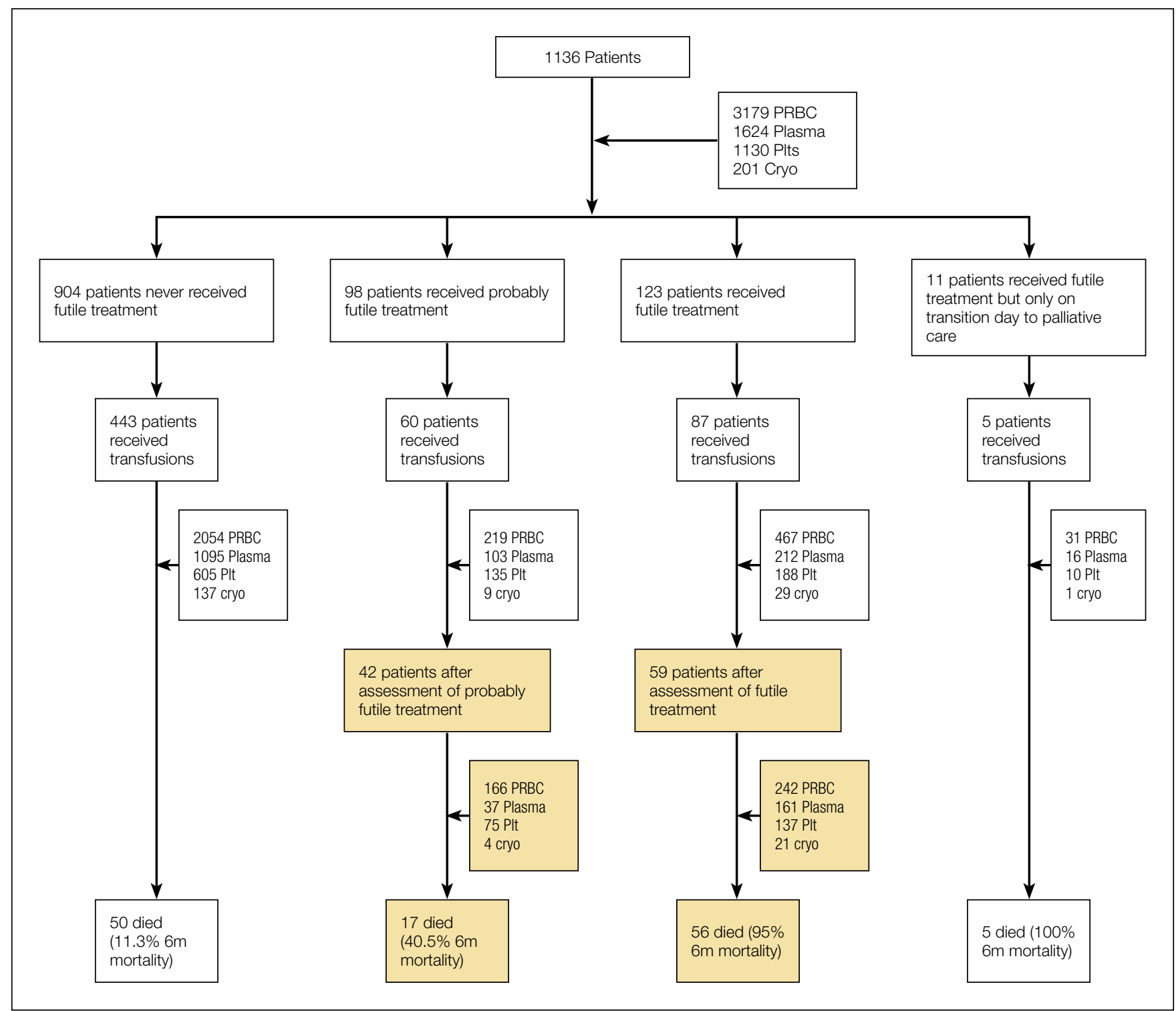

FIG. Derivation of the study sample, the blood products received and patient outcomes. Shaded boxes show transfusions that occurred after a patient was assessed as receiving probably futile or futile treatment. NOTE: Abbreviations: cryo, cryoprecipitate; m, month; PIt, platelet; PRBC, packed red blood cells

blood to preserve life in such compromised health states is testable. This proportion of blood provided to ICU patients perceived as receiving futile treatment $(7.6 \%)$ is similar to or greater than that lost due to wastage, which ranges from $0.1 \%$ to $6.7 \% .{ }^{14}$ While the loss of this small proportion of blood products due to expiration or procedural issues is probably unavoidable, but should be minimized as much as possible, the provision of blood products to patients receiving futile critical care is under the control of the healthcare team. This raises the question of how altruistic blood donors would feel about donating if they were aware that 1 of every 13 units transfused in the ICU would be given to a patient that the physician feels will not benefit. In turn, it raises the question of whether the physician should refrain from using these blood products for patients who will not benefit in ac- cordance with principles of evidence-based medicine, in order to ensure their availability for patients that will benefit.

This study has several limitations. Family/patient perspectives were not included in the assessment of futile treatment. It should also be recognized that the percentage of blood products provided to patients receiving inappropriate critical care is likely an underestimate as only blood product use during the 3 -month study period was included, as many of these patients were admitted to the ICU prior the study period, and/or remained in the ICU or hospital after this window.

\section{CONCLUSIONS}

Similar to other treatments provided to patients who are perceived to receive futile critical care, blood products represent a healthcare resource that has the potential to be used 
without achieving the goals of medicine. But unlike many other medical treatments, the ability to maintain an adequate blood supply for transfusion relies on altruistic blood donors, individuals who are simply motivated by a desire to achieve a healthcare good. ${ }^{13}$ Explicit guidelines on the use of blood products should be developed to ensure that the use of this precious resource achieves meaningful goals. These goals need to be transparently defined such that a physician's decision to not transfuse is expected as part of evidence-based medicine. Empiric research, educational interventions, and clearly delineated conflict-resolution processes may improve clinicians' ability to handle these difficult cases. ${ }^{15}$

Disclosure: T. Neville was supported by the UCLA CTSI KL2 UL1TR000124, the NIH-NIA 1K23AG047900 - 01A1, and the NIH Loan Repayment Program grant. This project was supported by a donation from Mary Kay Farley to RAND Health. The funder played no role in the design and conduct of the study; collection, management, analysis, and interpretation of the data; or preparation, review, or approval of the manuscript. The authors have no conflicts of interest to disclose.

\section{REFERENCES}

1. Palda VA, Bowman KW, McLean RF, Chapman MG. "Futile" care: do we provide it? Why? A semistructured, Canada-wide survey of intensive care unit doctors and nurses. J Crit Care. 2005;20:207-213.

2. Piers RD, Azoulay E, Ricou B, et al. Perceptions of appropriateness of care among European and Israeli intensive care unit nurses and physicians. JAMA. 2011;306:2694-2703.

3. Huang S, Dang H, Huynh W, Sambrook PJ, Goss AN. The healing of dental extraction sockets in patients with Type 2 diabetes on oral hypoglycaemics: a prospective cohort. Aust Dent J. 2013;58:89-93.

4. Angus DC, Barnato AE, Linde-Zwirble WT, et al. Use of intensive care at the end of life in the United States: an epidemiologic study. Crit Care Med. 2004;32:638-643.

5. Wunsch H, Linde-Zwirble WT, Harrison DA, Barnato AE, Rowan KM, Angus DC. Use of intensive care services during terminal hospitalizations in England and the United States. Am J Respir Crit Care Med. 2009;180:875-880.

6. Esserman L, Belkora J, Lenert L. Potentially ineffective care. A new outcome to assess the limits of critical care. JAMA. 1995;274:1544-1551.

7. Agency for Healthcare Research and Quality: HCUP facts and figures: statistics on hospital-based care in the United States. 2009. https://www.hcup-us.ahrq.gov/ reports/factsandfigures/2009/TOC_2009.jsp. Accessed July 15, 2016.

8. Goodnough LT, Maggio P, Hadhazy E, et al. Restrictive blood transfusion practices are associated with improved patient outcomes. Transfusion. 2014;54:2753-2759.

9. Shander AS, Goodnough LT. Blood transfusion as a quality indicator in cardiac surgery. JAMA. 2010;304:1610-1611.

10. Hebert PC, Wells G, Blajchman MA, et al. A multicenter, randomized, controlled clinical trial of transfusion requirements in critical care. Transfusion Requirements in Critical Care Investigators, Canadian Critical Care Trials Group. N Engl J Med. 1999;340:409-417.

11. Morton J, Anastassopoulos KP, Patel ST, et al. Frequency and outcomes of blood products transfusion across procedures and clinical conditions warranting inpatient care: an analysis of the 2004 healthcare cost and utilization project nationwide inpatient sample database. Am J Med Qual. 2010;25:289-296.

12. Shander A, Fink A, Javidroozi M, et al. Appropriateness of allogeneic red blood cell transfusion: the international consensus conference on transfusion outcomes. Transfus Med Rev. 2011;25:232-246 e53.

13. Bednall TC, Bove LL. Donating blood: a meta-analytic review of self-reported motivators and deterrents. Transfus Med Rev. 2011;25:317-334.

14. Heitmiller ES, Hill RB, Marshall CE, et al. Blood wastage reduction using Lean Sigma methodology. Transfusion. 2010;50:1887-1896.

15. Bosslet GT, Pope TM, Rubenfeld GD, et al. An Official ATS/AACN/ACCP/ ESICM/SCCM Policy Statement: Responding to Requests for Potentially Inappropriate Treatments in Intensive Care Units. Am J Respir Crit Care Med. 2015;191:1318-1330. 